\title{
Knockdown of IncRNA MIR4435-2HG and ST8SIA1 expression inhibits the proliferation, invasion and migration of prostate cancer cells in vitro and in vivo by blocking the activation of the FAK/AKT/ $\beta$-catenin signaling pathway
}

\author{
PENGYI XING $^{1 *}$, YE WANG $^{2^{*}}$, LI ZHANG $^{3}, \mathrm{CHAO} \mathrm{MA}^{1}$ and JIANPING LU ${ }^{1}$ \\ ${ }^{1}$ Department of Radiology, The First Affiliated Hospital of Naval Medical University, Shanghai 200433; \\ ${ }^{2}$ Department of Urology, Chinese People's Liberation Army (PLA) General Hospital/PLA Medical School, Beijing 100853; \\ ${ }^{3}$ Department of Endocrinology, PLA Joint Logistics Support Force No. 989 Hospital, Luoyang, Henan 471600, P.R. China
}

Received September 30, 2020; Accepted March 3, 2021

DOI: $10.3892 /$ ijmm.2021.4926

\begin{abstract}
Prostate cancer is a main health risk for males with a high incidence and mortality. The present study aimed to examine the effects of long non-coding RNA (lncRNA) MIR4435-2HG binding with ST8SIA1 on the proliferation, invasion and migration of prostate cancer cells via the activation of the FAK/AKT/ $\beta$-catenin signaling pathway. The expression of MIR4435-2HG and ST8SIA1 in prostate cancer cell lines, and the transfection efficacy were analyzed by RT-qPCR. The proliferation, clone formation ability, and the invasion and migration of transfected cells were detected by CCK-8 assay, clone formation assay, Transwell assay and wound healing assay, respectively. Plasmids were injected subcutaneously into mice to construct a xenograft tumor model. The expression levels of proteins related to proliferation, apoptosis, invasion and migration, and the FAK/AKT/ $\beta$-catenin pathway were detected by western blot analysis. The results revealed that MIR4435-2HG expression was increased in the prostate cancer cell lines and MIR4435-2HG expression was the highest in the PC-3 cells. Interference with MIR4435-2HG inhibited the proliferation, clone formation ability, and the invasion and migration of PC-3 cells, as well as tumor growth by suppressing the activation of the FAK/AKT/ $\beta$-catenin signaling pathway. MIR4435-2HG was demonstrated to target ST8SIA1. ST8SIA1 expression was also increased in the prostate cancer cell lines and MIR4435-2HG expression was the
\end{abstract}

Correspondence to: Dr Jianping Lu, Department of Radiology, The First Affiliated Hospital of Naval Medical University, 168 Changhai Road, Yangpu, Shanghai 200433, P.R. China

E-mail: cjr.lujianping@vip.163.com

*Contributed equally

Key words: IncRNA MIR4435-2HG, ST8SIA1, prostate cancer cells, FAK/AKT/ $\beta$-catenin signaling pathway highest in the PC-3 cells. Interference with ST8SIA1 inhibited the promoting effects of MIR4435-2HG on the proliferation, invasion and migration of PC-3 cells, as well as tumor growth by suppressing the activation of the FAK/AKT/ $\beta$-catenin signaling pathway. On the whole, the present study demonstrates that interference with MIR4435-2HG, combined with ST8SIA1, inhibits the proliferation, invasion and migration of prostate cancer cells in vitro and in vivo by blocking the activation of the FAK/AKT/ $\beta$-catenin signaling pathway.

\section{Introduction}

Prostate cancer has the second highest incidence and fifth highest mortality rates among all malignancies affecting males worldwide. According to the global cancer data reported in 2018 , the number of new prostate cancer cases worldwide was estimated to be $\sim 1,276,106$ annually, accounting for $13.5 \%$ of all new cases of male cancer in with a corresponding mortality rate of $6.7 \%$ (1). The incidence rate of prostate cancer in China has also been increasing annually and this disease has become one of the problems affecting the health of males in China. In recent years, the incidence rate of prostate cancer is 6th among malignant tumors affecting males, whereas it is mainly distributed in the age group $>60$ years and reaches a peak in the age group of 80 years (2). The 5-year survival rate of patients with advanced prostate cancer is $\sim 30 \%$ compared with the 5-year survival rate of $>99 \%$ for localized or locally advanced prostate cancer (3).

Long non-coding RNAs (lncRNAs) have been extensively investigated with regard to their involvement in tumor progression. Recently, it was reported that multiple lncRNAs play an important role in prostate cancer (4-8). IncRNA MIR4435-2HG, also known as LINC00978, has been shown to be highly expressed in hepatocellular carcinoma, bladder, lung and gastric cancer (9-12). The knockdown of MIR4435-2HG expression has been shown to inhibit the proliferation, invasion and migration of lung and bladder cancer cells $(9,10)$. A previous study demonstrated that lncRNA MIR4435-2HG induced $\beta$-catenin expression in gastric cancer cells by 
combining with desmoplakin to promote their proliferation, invasion and migration (11). MIR4435-2HG has been shown to promote the proliferation and metastasis of hepatocellular carcinoma cells (12).

Starbase (http://starbase.sysu.edu.cn/index.php) has predicted that MIR4435-2HG targets ST8SIA1. ST8SIA1 expression has been found to be increased in breast cancer tissues and cells, and its inhibition completely suppresses tumor growth in vivo and the metastasis of triple-negative breast cancer cells (13). ST8SIA1 has been shown to be highly expressed in colorectal cancer tissues and HCT-8/5-FU cells and it can promote the proliferation, invasion and migration of colon cancer cells (14). However, the expression levels and role of ST8SIA1 in prostate cancer cells remain unknown. In addition, ST8SIA1 activates the FAK/AKT/mammalian target of rapamycin (mTOR) signaling pathway to promote the progression of breast cancer (13). The AKT/ $\beta$-catenin signaling pathway is a classic cancer-promoting signaling pathway (15-17).

Therefore, the aim of the present study was to examine the effects of miR4435-2HG binding to ST8SIA1 on the proliferation, invasion and migration of prostate cancer cells and to explore the associated mechanism of action mediated by the activation of the FAK/AKT/ $\beta$-catenin signaling pathway.

\section{Materials and methods}

Cells and cell culture. The prostate cell line, WPMY-1 (CRL-2854), and the prostate cancer cell lines, VCaP (CRL-2876), LNCaP (CRL-1740), DU145 (HTB-81) and PC-3 (CRL-1435), were purchased from the American Type Culture Collection (ATCC). The prostate cell line was cultured in KSLM medium containing 10\% FBS (Gibco; Thermo Fisher Scientific, Inc.) and the prostate cancer cell lines were cultured in RPMI-1640 medium containing 10\% FBS in an incubator at $37^{\circ} \mathrm{C}$ in the presence of $5 \% \mathrm{CO}_{2}$ and saturated humidity.

Cell transfection. When the cells reached $80 \%$ confluency, they were transfected with the plasmids containing pcDNA-negative control (NC) (5 nM) and pcDNA-miR4435-2HG (5 nM) (Invitrogen; Thermo Fisher Scientific, Inc.) and the sequences short hairpin (sh)RNA-NC (5 nM), shRNA-miR4435-2HG-1 (5 nM), shRNA-miR4435-2HG-2 (5 nM), shRNA-ST8SIA1-1 $(5 \mathrm{nM})$ and shRNA-ST8SIA1-2 (5 nM) (Guangzhou RiboBio Co., Ltd.) using Lipofectamine ${ }^{\circledR} 2000$ (Invitrogen; Thermo Fisher Scientific, Inc.). After $24 \mathrm{~h}$ of transfection, subsequent experiments were conducted.

Reverse transcription-quantitative PCR (RT-qPCR) analysis. The TRIzol ${ }^{\circledR}$ kit was used to extract total RNA from the prostate cancer cells and the reverse transcription kit (TransGen Biotech Co., Ltd.) was used to reverse transcribe this into cDNA. The AceQ qPCR SYBR-Green Master Mix (Bio-Rad Laboratories, Inc.) was used for the qPCR reaction. The thermocycling conditions were as follows: Initial denaturation at $96^{\circ} \mathrm{C}$ for $4 \mathrm{~min}$; followed by 40 cycles of denaturation at $95^{\circ} \mathrm{C}$ for $20 \mathrm{sec}$, annealing at $60^{\circ} \mathrm{C}$ for $30 \mathrm{sec}$ and extension at $72^{\circ} \mathrm{C}$ for $30 \mathrm{sec}$. The primer sequences were as follows: lncRNA MIR4435-2HG forward, 5'-GGAAGTGGTGGCTATGAGTCAG-3' and reverse, 5'-TGT CAATTTGAAACTTAAAAAGCAG-3'; ST8SIA1 forward,
5'-TACTCTCTCTTCCCACAGG-3' and reverse, 5'-GACAAA GGAGGGAGATTGC-3'; GAPDH forward, 5'-CATGAGAAG TATGACAACAGCCT-3' and reverse, 5'-AGTCCTTCCACG ATACCAAAGT-3'. GAPDH was used as an internal reference to calculate the expression levels of miR4435-2HG and ST8SIA1 mRNA using the $2^{-\Delta \Delta C q}$ method (18).

Cell Counting kit (CCK)-8 assay. Following transfection for $24 \mathrm{~h}$, the prostate cancer cells were seeded into 96 -well plates at a density of $4 \times 10^{3}$ cells/well and cultured for 24,48 and $72 \mathrm{~h}$. A total of $10 \mu$ CCK-8 solution was added to each well and the plate was incubated at $37^{\circ} \mathrm{C}$ for $4 \mathrm{~h}$. The absorbance value was measured at $450 \mathrm{~nm}$ using a microplate reader (Multiskan MK3; Thermo Fisher Scientific, Inc.).

Colony formation assay. Following transfection for $24 \mathrm{~h}$, the prostate cancer cells were collected, resuspended in medium and seeded into single-cell suspension. Subsequently, the cells were counted and their density was adjusted to 500 cells per well. Following seeding, the KSLM medium was added to each well to a total volume of $300 \mu 1$. Following 14 days of cell culture, the culture medium was removed and the cells were rinsed with PBS twice. A total of $200 \mu 1$ and $1 \%$ crystal violet dye solution (Beyotime Institute of Biotechnology) was added to each well, which was fully covered at the bottom of the hole. Following $20 \mathrm{~min}$ of incubation at room temperature, the plate was washed using tap water and dried for assay detection.

Wound healing assay. The prostate cancer cells were transfected, cultured for $24 \mathrm{~h}$ and collected. The cells were resuspended in serum-free medium and incubated in a 6-well plate $\left(5 \times 10^{4}\right)$ (the incubated cells were covered with a layer of the culture plate the following day) for $24 \mathrm{~h}$. Following incubation at room temperature for $24 \mathrm{~h}$, the cells were scratched with a $200-\mu 1$ sterile pipette tip and washed with PBS thrice. The migration of the cells was observed and images were captured at 0 and $24 \mathrm{~h}$ using a light microscope (magnification, x100; Olympus Corporation).

Transwell assay. Matrigel was dissolved overnight at $4^{\circ} \mathrm{C}$ and diluted in pre-cooled serum-free medium. A total of $40 \mu 1$ Matrigel was added to a pre-cooled Transwell chamber, which was allowed to solidify following incubation for $2 \mathrm{~h}$ at $37^{\circ} \mathrm{C}$. The transfected cells $\left(1 \times 10^{5}\right)$ were mixed with $100 \mu \mathrm{l}$ serum-free DMEM and added to the upper chamber. A total of $600 \mu \mathrm{l}$ complete medium was added to the lower chamber. Following incubation of the cells at $37^{\circ} \mathrm{C}$ with $5 \% \mathrm{CO}_{2}$ for $24 \mathrm{~h}$, the cells in the upper chamber were wiped using a cotton swab, fixed with $4 \%$ paraformaldehyde for $15 \mathrm{~min}$, washed with PBS once, stained with crystal violet for $10 \mathrm{~min}$ at room temperature, washed with PBS again, imaged and counted under a light microscope (Olympus Corporation).

Western blot analysis. The transfected cells and tumor tissues were lysed in RIPA lysis buffer (CWBio) on ice for $30 \mathrm{~min}$ and the mixture was centrifuged for $15 \mathrm{~min}$ $\left(4^{\circ} \mathrm{C}, 14,000 \mathrm{x} \mathrm{g}\right)$ to obtain the supernatant. Following quantitative analysis using a BCA kit (Beyotime Institute of Biotechnology), the proteins were separated on $10 \%$ sodium 
dodecyl sulfate polyacrylamide gels by electrophoresis, transferred to polyvinylidene difluoride membranes and incubated with 5\% non-fat milk for $2 \mathrm{~h}$ at room temperature. Subsequently, the membranes were incubated with antibodies against matrix metalloproteinase (MMP)2 (ab92536; dilution, 1:1,000), MMP9 (ab76003; dilution, 1:1,000), Ki67 (ab92742; dilution, 1:5,000), survivin (ab208938; dilution, $1: 1,000), \beta$-catenin (ab6302; dilution, $1: 4,000$ ), c-MYC (ab32072; dilution, 1:1,000), cyclin D1 (ab16663; dilution, 1:200), phosphorylated (p)-FAK (ab81298; dilution, 1:1,000), p-AKT (ab81298; dilution, 1:1,000) and GAPDH (ab9485; 1:1,000) (all from Abcam) at $4^{\circ} \mathrm{C}$ overnight. The following day, the membranes were incubated with a horseradish peroxidase-labeled secondary antibody (\#7074; 1:1,000; Cell Signaling Technology, Inc.) at room temperature for $1 \mathrm{~h}$ and visualized using ECL reagents (Research-bio). Relative protein expression was quantified using Image-Pro Plus software (version 6.0; Media Cybernetics, Inc.).

Xenograft model. A total of 20 male nude mice were grown for 6-8 weeks with a weight of $18 \pm 2 \mathrm{~g}$ and were provided from Shanghai Jesijie Experimental Animal Co., Ltd. These mice were divided $(n=5)$ randomly into the following 4 groups: shRNA-MIR4435-2HG, pcDNA-miR4435-2HG, pcDNA-mi R4435-2HG + shRNA-ST8SIA1 and the control. PC-3 cells were suspended with PBS. A total of $200 \mu \mathrm{l}\left(1 \times 10^{4} \mathrm{cells} / \mu \mathrm{l}\right)$ cell suspension was transplanted subcutaneously into the back of right forelimb of the mice. The body weight and tumor volume were recorded on days $1,5,10,15$ and 20 . Tumor volume was calculated as follows: Tumor volume $=$ (length $\mathrm{x}$ width $\mathrm{x}$ width)/2. At the end of the experiment (day 20), the 20 mice were euthanized with pentobarbital sodium ( $165 \mathrm{mg} / \mathrm{kg}$, i.p.) and death was confirmed by monitoring the heartbeat. The tumors were weighed, and the maximum tumor diameter and volume obtained were $1.1 \mathrm{~cm}$ and $800 \mathrm{~mm}^{3}$, respectively. All procedures were approved by the Animal Care and Use Committee of the First Affiliated Hospital of Naval Medical University.

RNA binding protein immunoprecipitation (RIP). The binding sites of MIR4435-2HG and ST8SIA1 are predicted by Starbase (http://starbase.sysu.edu.cn/index.php). RIP assays were performed using the Magna RIP Kit (Millipore, Bedford, MA, USA) according to manufacturer's instructions. The prostate cancer cells were lysed with RIPA lysis buffer on ice. The lysate was incubated with magnetic beads conjugated with $\mathrm{IgG}$ antibody, which were pre-cleaned with RIP washing buffer twice. RNA-protein complexes were immunoprecipitated with the Pierce Magnetic RNA-Protein Pull-Down kit (Pierce; Thermo Fisher Scientific, Inc.). Total RNA was extracted using TRIzol ${ }^{\circledR}$ reagent and RT-qPCR was performed to detect the expression levels of miR4435-2HG.

Statistical analysis. SPSS 22.0 (IBM Corp.) software was used for statistical analyses. All the data are presented as the means \pm standard deviation. Two-group comparisons were analyzed with a Student's t-test, while comparisons between multiple groups were analyzed by one-way ANOVA with Tukey's post hoc test. A value of $\mathrm{P}<0.05$ was considered to indicate a statistically significant difference.

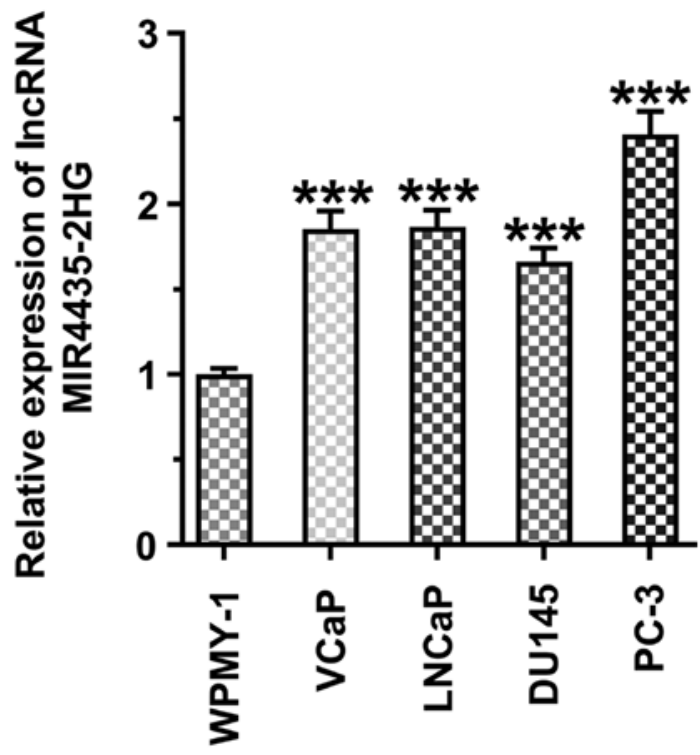

Figure 1. MIR4435-2HG expression is increased in prostate cancer cell lines. MIR4435-2HG expression in the prostate cell line (WPMY-1 cells) and prostate cancer cell lines (VCaP, LNCaP, DU145 and PC-3 cells) was detected by RT-qPCR. ${ }^{* * * *} \mathrm{P}<0.001$ vs. the WPMY-1 cells.

\section{Results}

MIR4435-2HG expression levels are increased in prostate cancer cell lines. The MI4435-2HG expression levels were increased in the prostate cancer cell lines (VCaP, LNCaP, DU145 and PC-3 cells) compared with those in the WPMY-1 cells. miR4435-2HG expression was highest in the PC-3 cells, and these cells were thus selected for use in subsequent experiments (Fig. 1).

Knockdown of MIR4435-2HG expression inhibits the proliferation of prostate cancer cells. The MIR4435-2HG expression levels were decreased in the PC-3 cells transfected with shRNA-MIR4435-2HG-1/2. The MIR4435-2HG expression levels in the shRNA-MIR4435-2HG-1 group were lower than those in the shRNA-MIR4435-2HG-2 group and shRNA-MIR4435-2HG-1 was thus selected for use in subsequent experiments (Fig. 2A). The knockdown of MIR4435-2HG expression suppressed the viability (Fig. 2B) and the clone formation ability (Fig. 2C) of the PC-3 cells.

Knockdown of MIR4435-2HG expression inhibits the invasion and migration of prostate cancer cells. The knockdown of MIR4435-2HG expression inhibited the migration (Fig. 3A and B) and invasion (Fig. 3C and D) of PC-3 cells. In addition, the knockdown of MIR4435-2HG expression led to the downregulation of the expression levels of MMP2 and MMP9 in PC-3 cells (Fig. 3E).

Knockdown of MIR4435-2HG expression inhibits the growth of prostate cancer cells in vivo. The visual investigation of euthanized mice and of their corresponding tumors is presented in Fig. 4. The knockdown of MIR4435-2HG expression decreased the tumor weight on the 20th day (Fig. 5A), whereas it also caused a gradual decrease in the body weight of the mice resulting, in a decrease in the tumor volume from 


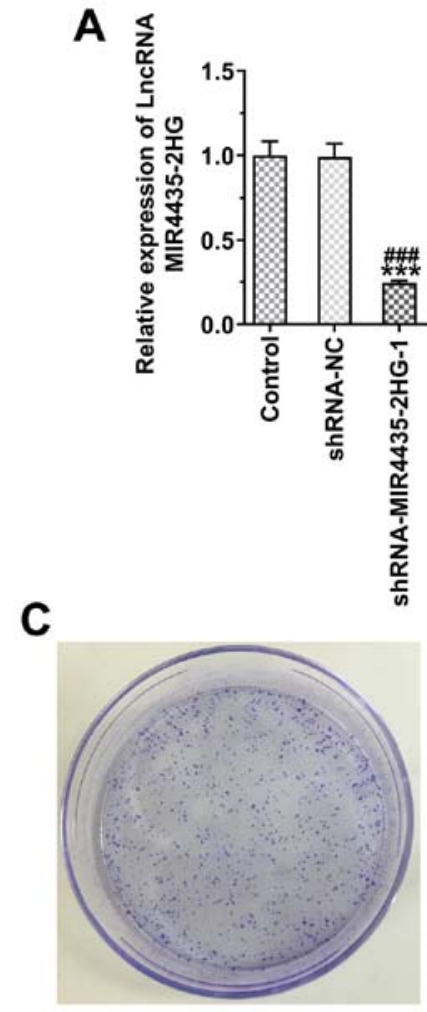

Control
B

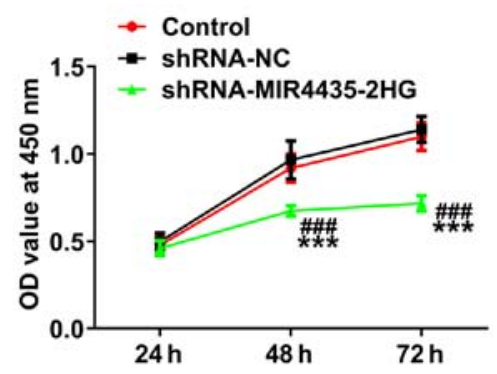

Figure 2. Interference with MIR4435-2HG inhibits the proliferation of prostate cancer cells. (A) MIR4435-2HG expression in PC-3 cells transfected with shRNA-MIR4435-2HG-1/2 was detected by RT-qPCR. ${ }^{* * *} \mathrm{P}<0.001$ vs. control group; ${ }^{\# \# \#} \mathrm{P}<0.001$ vs. shRNA-NC group; ${ }^{\wedge} \mathrm{P}<0.05$ vs. shRNA-MIR4435-2HG-1 group. (B) The proliferation of PC-3 cells transfected with shRNA-MIR4435-2HG was analyzed by CCK-8 assay. ${ }^{* * * *} \mathrm{P}<0.001$ vs. control group; ${ }^{\# \# \#} \mathrm{P}<0.001$ vs. shRNA-NC group. (C) The clone formation ability of PC-3 cells transfected with shRNA-MIR4435-2HG was examined by clone formation assay.
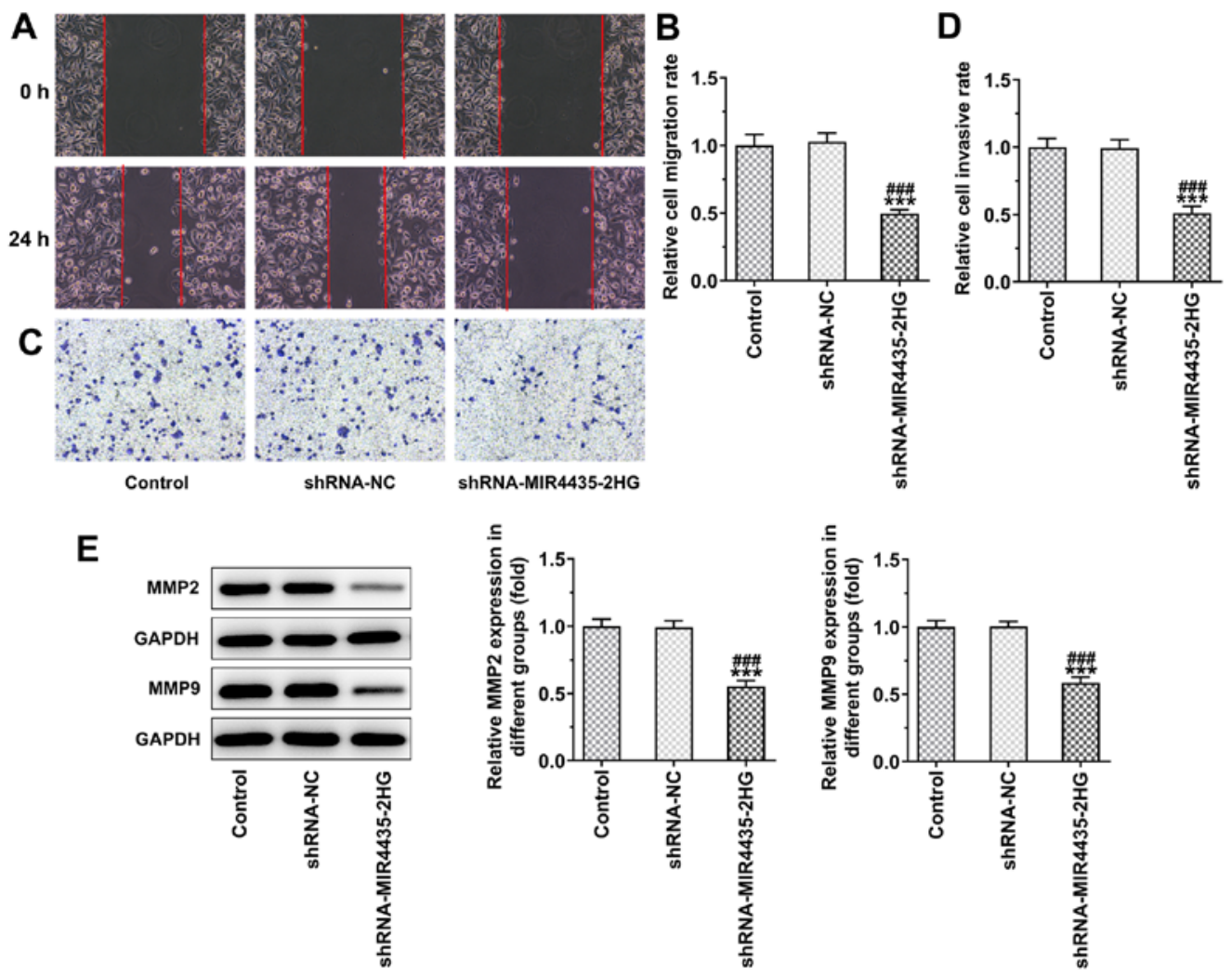

Figure 3. Interference with MIR4435-2HG inhibits the invasion and migration of prostate cancer cells. (A and B) The migration of PC-3 cells transfected with shRNA-MIR4435-2HG was analyzed by wound healing assay (magnification, x100). (C and D) The invasion of PC-3 cells transfected with shRNA-MIR4435-2HG was analyzed by Transwell assay (magnification, x100). (E) The expression of MMP2 and MMP9 in PC-3 cells transfected with shRNA-MIR4435-2HG was detected by western blot analysis. ${ }^{* * *} \mathrm{P}<0.001$ vs. control group; ${ }^{\# \# "} \mathrm{P}<0.001$ vs. shRNA-NC group. 

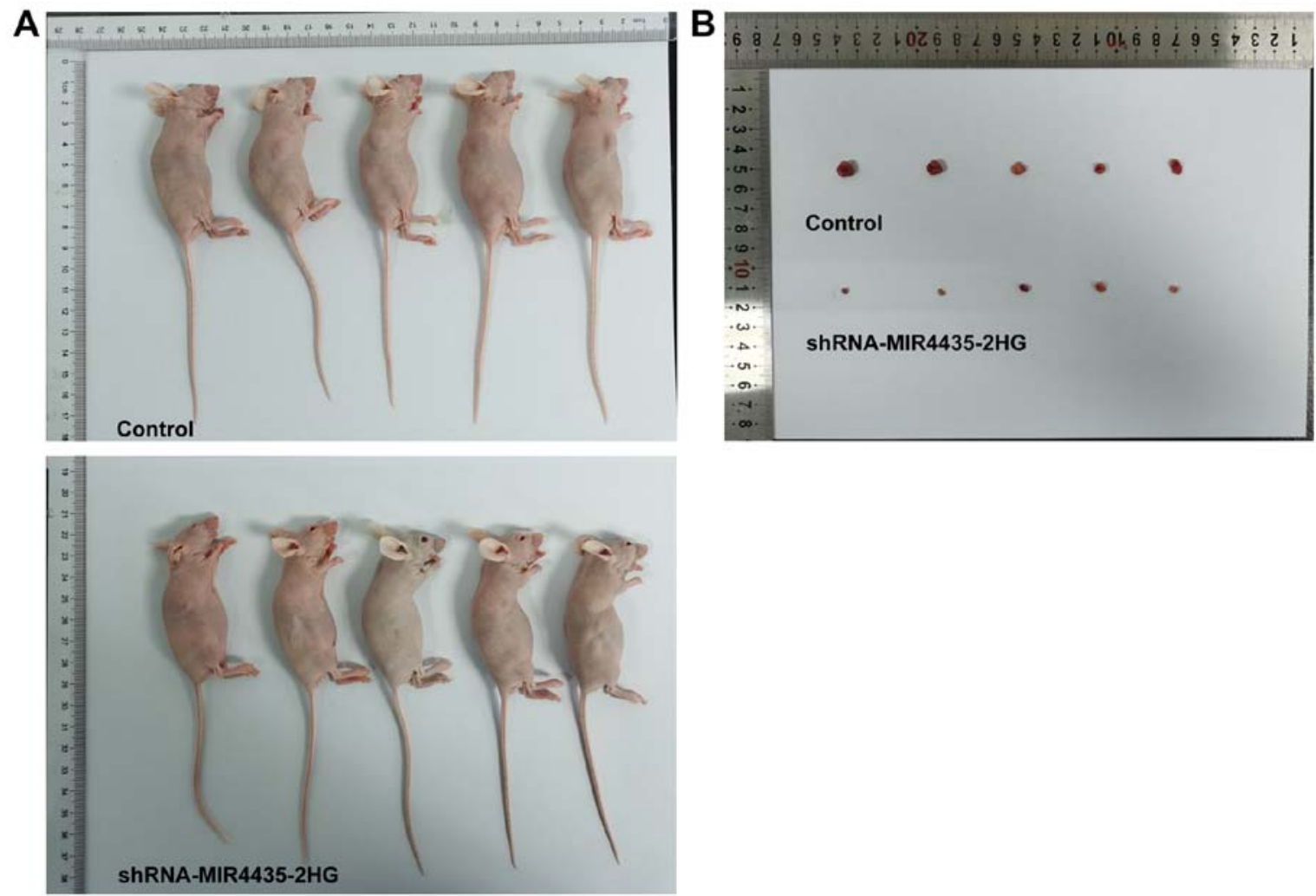

Figure 4. Interference with MIR4435-2HG inhibits the growth of prostate cancer cells in vivo. (A) The appearance of euthanized mice subcutaneously injected with PC-3 cells transfected with shRNA-MIR4435-2HG. (B) Tumor appearance.

the 1st to the 20th day (Fig. 5B and C). Moreover, the knockdown of MIR4435-2HG expression suppressed the expression levels of Ki67, survivin, MMP2 and MMP9 in the tumor tissues (Fig. 5D).

Knockdown of MIR4435-2HG expression inhibits the activation of the FAK/AKT/ $\beta$-catenin signaling pathway in vitro and in vivo. The knockdown of MIR4435-2HG expression in the transfected PC-3 cells decreased the expression levels of $\beta$-catenin, c-MYC and cyclin D1 (Fig. 6A). The expression levels of $\beta$-catenin, c-MYC and cyclin D1 in the tumor tissues were also downregulated in the shRNA-MIR4435-2HG group compared to those of the control group (Fig. 6B).

MIR4435-2HG binds to ST8SIAI in prostate cancer cells. The binding sites of MIR4435-2HG and ST8SIA1 are illustrated in Fig. 7A. RIP assay indicated that MIR4435-2HG bound to ST8SIA1 in prostate cancer cells (Fig. 7B). ST8SIA1 expression was also increased in the prostate cancer cells compared with the WPMY-1 cells, whereas the highest expression was noted in the PC-3 cells (Fig. 7C). The knockdown of MIR4435-2HG expression suppressed the expression of ST8SIA1 (Fig. 7D).

Knockdown of ST8SIA1 expression inhibits the effects of MIR4435-2HG on the proliferation of prostate cancer cells. MIR4435-2HG expression was increased in the PC-3 cells transfected with pcDNA-MIR4435-2HG (Fig. 8A), whereas ST8SIA1 expression was decreased in the PC- 3 cells transfected with shRNA-ST8SIA1-1/2. ST8SIA1 protein expression was lower in the shRNA-ST8SIA1-1 group compared with that in the shRNA-ST8SIA1-2 group (Fig. 8B), whereas ST8SIA1 mRNA expression in the shRNA-ST8SIA1-2 group demonstrated similar changes to those noted for the protein expression levels of the ST8SIA1 (Fig. 8C). MIR4435-2HG overexpression promoted the proliferation of the PC-3 cells, which was reversed following the knockdown of ST8SIA1 expression (Fig. 8D).

Knockdown of ST8SIA1 expression inhibits the effects of MIR4435-2HG on the invasion and migration of prostate cancer cells. The invasion and migration of the PC-3 cells was observed by wound healing and the Transwell assays following cell transfection (Fig. 9A and B). MIR4435-2HG overexpression promoted the migration (Fig. 9C) and invasion (Fig. 9D) of PC-3 cells, which was reversed following the knockdown of ST8SIA1 expression. MIR4435-2HG overexpression also increased the levels of MMP2 and MMP9 in PC-3 cells, which were reversed following the knockdown of ST8SIA1 expression (Fig. 9E).

Knockdown of ST8SIA1 expression inhibits the effects of MIR4435-2HG on the growth of prostate cancer cells in vivo. The visual investigation of euthanized mice and their tumors is presented in Fig. 10. MIR4435-2HG overexpression increased tumor weight in the mice and the knockdown of ST8SIA1 expression suppressed the effects of MIR4435-2HG overexpression on cell proliferation on day 20 (Fig. 11A). As the time period of treatment increased, the body weights (Fig. 11B) of the mice and their tumor volume (Fig. 11C) gradually increased 

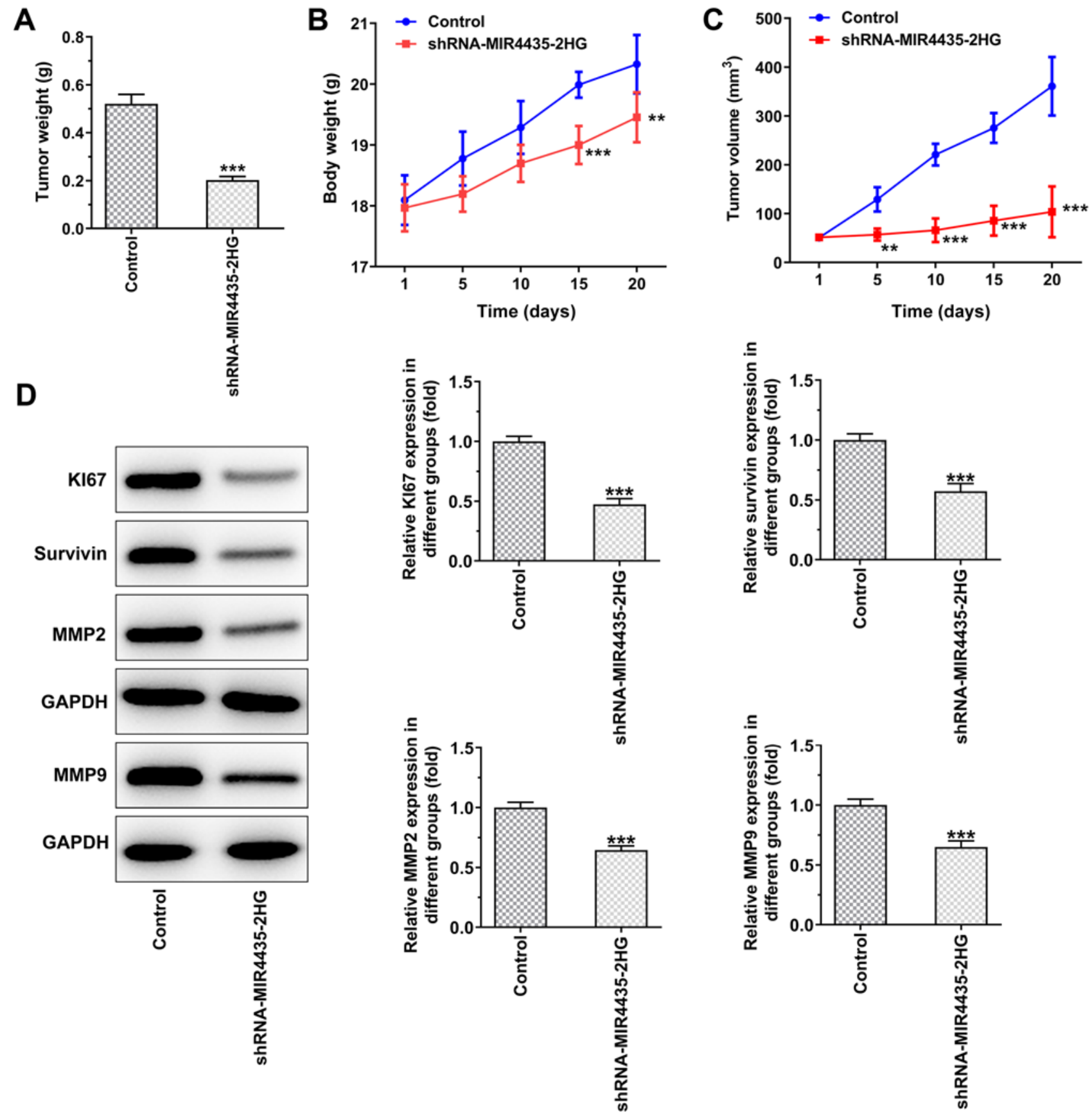

Figure 5. Interference with MIR4435-2HG inhibits the growth of prostate cancer cells in vivo. (A) Tumor weight. (B) Mouse body weight changing from the 1st to the 20th day. (C) Tumor volume changing from 1st to the 20th day. (D) The expression of KI67, survivin, MMP2 and MMP9 in tumor tissues was detected by western blot analysis. ${ }^{* *} \mathrm{P}<0.01$ and ${ }^{* * *} \mathrm{P}<0.001$ vs. control group.

in the pcDNA-MIR4435-2HG group. The increase noted in the pcDNA-MIR4435-2HG + shRNA-ST8SIA1 group was lower than that in the pcDNA-MIR4435-2HG group. MIR4435-2HG overexpression also promoted the expression of KI67, survivin, MMP2 and MMP9 in the tumor tissues, whereas the knockdown of ST8SIA1 expression attenuated the effects of MIR4435-2HG overexpression (Fig. 11D).

MIR4435-2HG overexpression activates the FAK/AKT/ $\beta$ catenin signaling pathway, which is inhibited following the knockdown of ST8SIA1 expression. MIR4435-2HG overexpression caused an upregulation in the expression levels of p-FAK, p-AKT, $\beta$-catenin, c-MYC and cyclin D1, which was inhibited following the knockdown of ST8SIA1 expression in PC-3 cells (Fig. 12A) and in tumor tissues (Fig. 12B).

\section{Discussion}

Prostate cancer is a malignant disease, which affects the health of male patients. It is not easily diagnosed due to the lack of specific tumor markers present in the early stages of the disease. Therefore, effective treatment is not usually applied at an early stage and the disease rapidly progresses (19). The proliferation and invasion of the cells in malignant tumors remains a major obstacle in the treatment process of this disease. The reduction in the proliferative and invasive rate is conducive to 
A

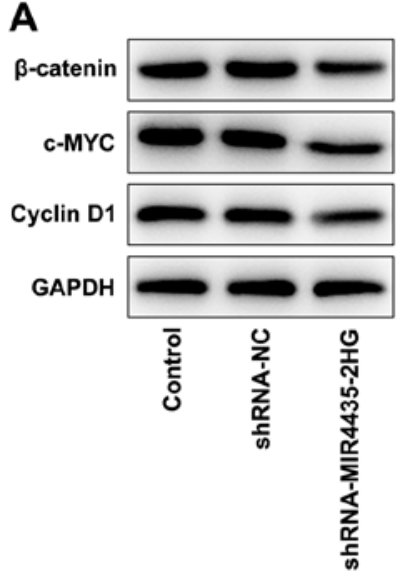

B

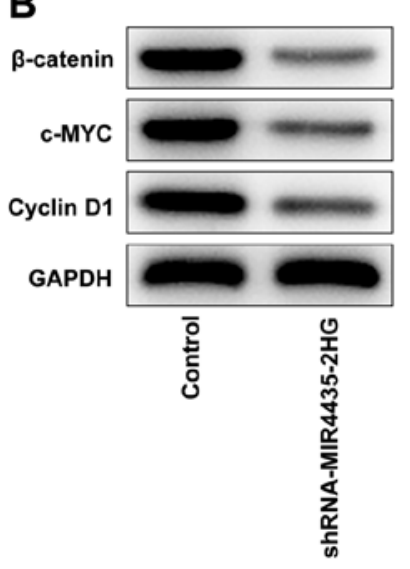

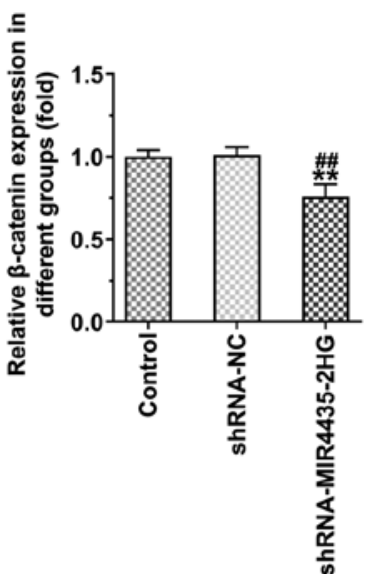

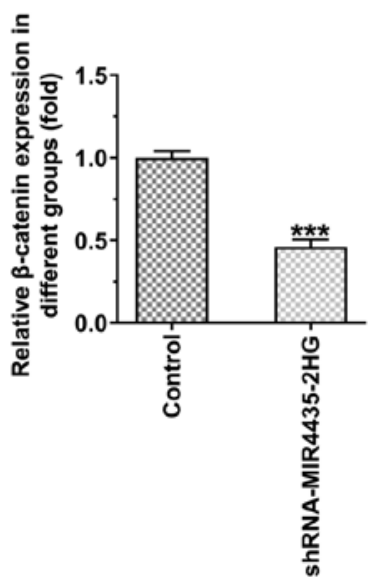

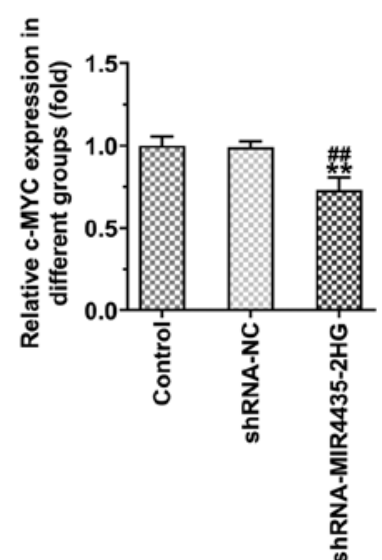
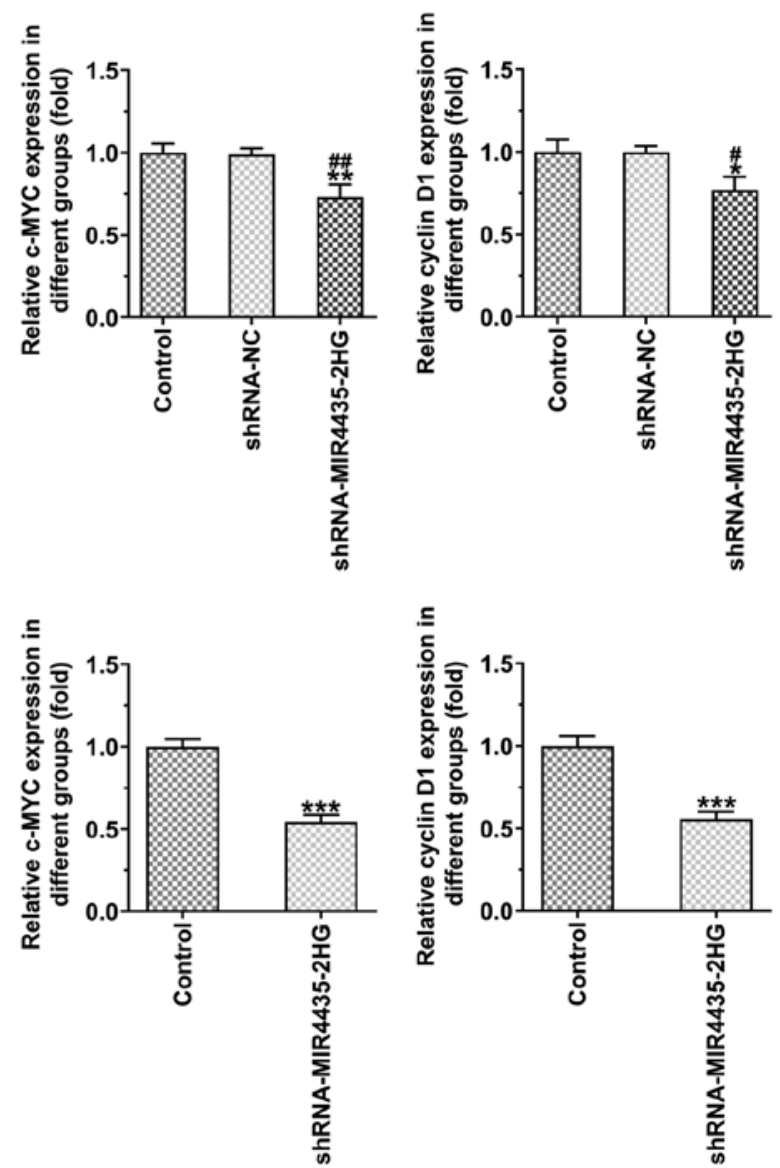

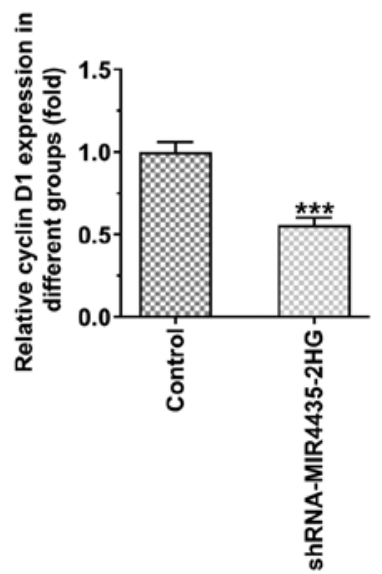

Figure 6. Interference with MIR4435-2HG inhibits the activation of FAK-AKT- $\beta$-catenin signaling pathway in vitro and in vivo. (A) The expression of $\beta$-catenin, c-MYC and cyclin D1 in PC-3 cells transfected with shRNA-MIR4435-2HG was detected by western blot analysis. " $\mathrm{P}<0.05$ and ${ }^{* * *} \mathrm{P}<0.01$ vs. control group; ${ }^{\#} \mathrm{P}<0.05$ and ${ }^{\# \#} \mathrm{P}<0.01$ vs. shRNA-NC group. (B) The expression of $\beta$-catenin, c-MYC and cyclin D1 in tumor tissues of mice subcutaneously injected with PC-3 cells transfected with shRNA-MIR4435-2HG was detected by western blot analysis. ${ }^{* * *} \mathrm{P}<0.001$ vs. control group.

\section{A MIR4435-2HG: 5' GGAACUC-C-CGG 3' IIII II I II}
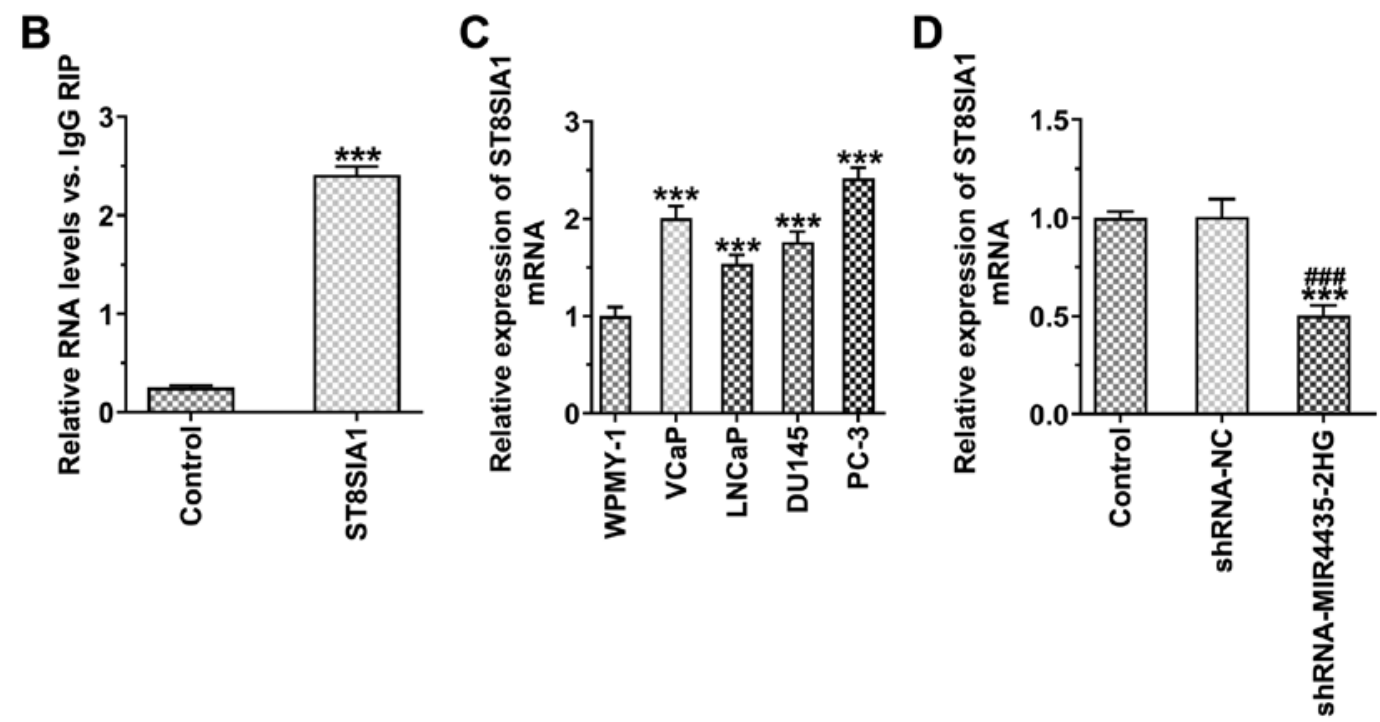

Figure 7. MIR4435-2HG binds to ST8SIA1 in prostate cancer cells. (A) The binding sites of MIR4435-2HG and ST8SIA1. (B) MIR4435-2HG was combined with ST8SIA1. ${ }^{* * *} \mathrm{P}<0.001$ vs. control group. (C) ST8SIA1 expression in a prostate cell line (WPMY-1 cells) and prostate cancer cell lines (VCaP, LNCaP, DU145 and PC-3 cells) detected by RT-qPCR. ${ }^{* * *} \mathrm{P}<0.001$ vs. WPMY-1 group. (D) ST8SIA1 expression in PC-3 cells transfected with shRNA-MIR4435-2HG detected by RT-qPCR. ${ }^{* * *} \mathrm{P}<0.001$ vs. control group; ${ }^{\# \#} \mathrm{P}<0.001$ vs. shRNA-NC group. 


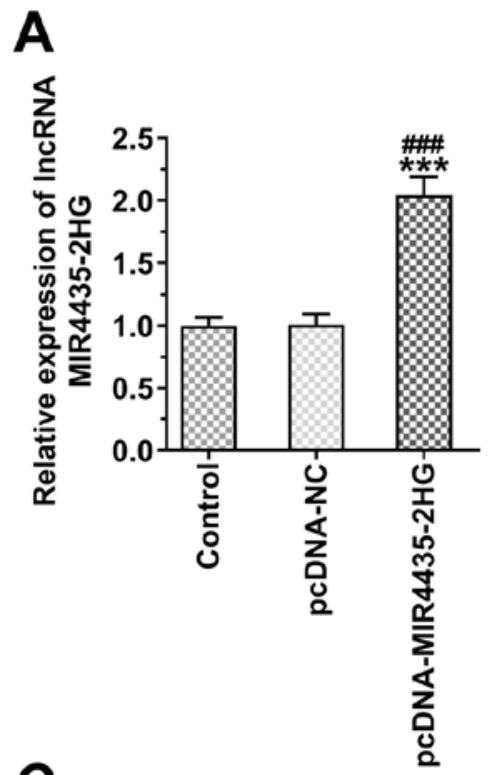

B
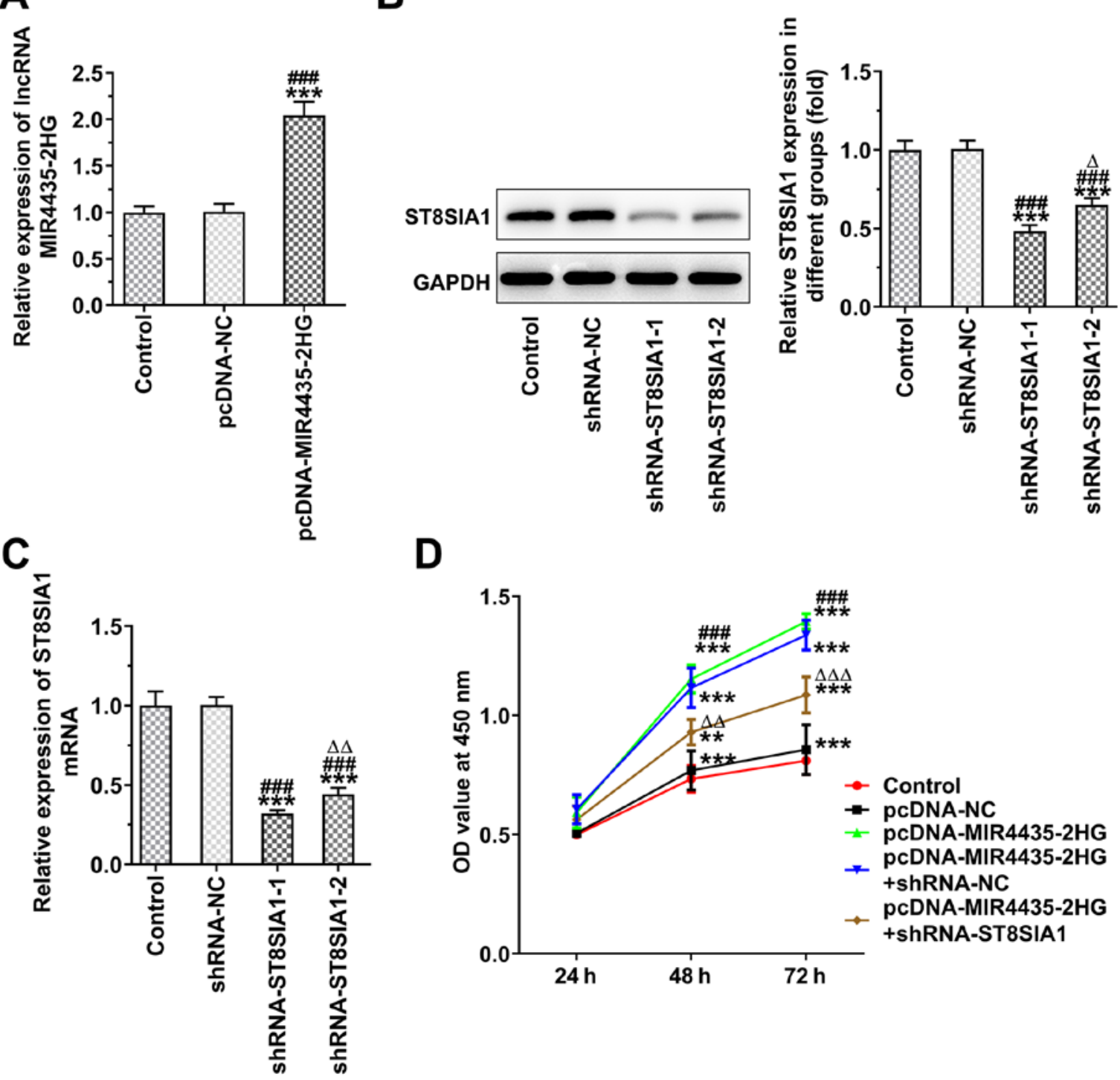

D

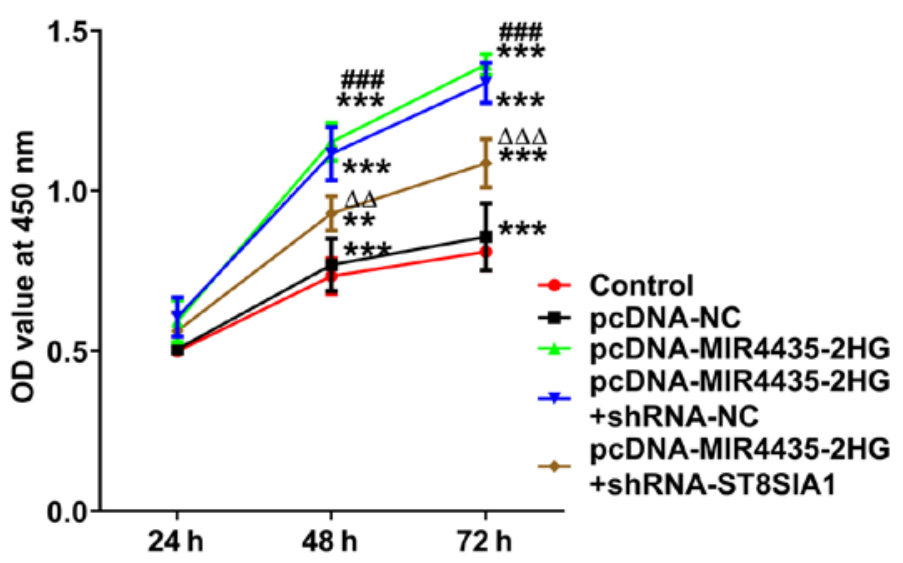

Figure 8. Interference with ST8SIA1 inhibits the promoting effects of MIR4435-2HG on the proliferation of prostate cancer cells. (A) MIR4435-2HG expression in PC-3 cells transfected with pcDNA-MIR4435-2HG detected by RT-qPCR. ${ }^{* * *} \mathrm{P}<0.001$ vs. control group; ${ }^{\# \#} \mathrm{P}<0.001$ vs. pcDNA-NC group. (B) ST8SIA1 protein expression in PC-3 cells transfected with shRNA-ST8SIA1-1/2 detected by western blot analysis. ${ }^{* * * *} \mathrm{P}<0.001$ vs. control group; ${ }^{\# \# \#} \mathrm{P}<0.001$ vs. shRNA-NC group; ${ }^{\triangle} \mathrm{P}<0.05$ vs. shRNA-ST8SIA1-1 group. (C) ST8SIA1 mRNA expression in PC-3 cells transfected with shRNA-ST8SIA1-1/2 detected by RT-qPCR. ${ }^{* * *} \mathrm{P}<0.001$ vs. control group; ${ }^{\# \# \#} \mathrm{P}<0.001$ vs. shRNA-NC group; ${ }^{\Delta \Lambda} \mathrm{P}<0.01$ vs. shRNA-ST8SIA1-1 group. (D) The proliferation of PC-3 cells transfected with pcDNA-MIR4435-2HG and shRNA-ST8SIA1 was analyzed by CCK-8 assay. ${ }^{* *} \mathrm{P}<0.01$ and ${ }^{* * *} \mathrm{P}<0.001$ vs. control group; ${ }^{\# \# \#} \mathrm{P}<0.001 \mathrm{vs}$. pcDNA-NC group. ${ }^{\Delta \Delta} \mathrm{P}<0.01$ and ${ }^{\Delta \Delta \Delta} \mathrm{P}<0.001$ vs. pcDNA-MIR4435-2HG + shRNA-NC group.

the remission of the disease. Therefore, research on the targets genes that can reduce the proliferation and invasion of the cells may result in the treatment of this disease (20).

lncRNAs affect the proliferation, invasion and migration of multiple cancer types. MIR4435-2HG expression has been shown to be upregulated in gastric cancer (21), hepatocellular carcinoma (22), glioblastoma (23), colorectal cancer (24) and oral squamous cell carcinoma (25). This elevated expression promotes the proliferation, invasion and migration of the aforementioned cancer cell types. In the present study, MIR4435-2HG expression was also found to be elevated in prostate cancer cells, and the knockdown of its expression inhibited the proliferation, clone formation ability, invasion and migration of PC-3 cells in vitro as well as their tumor growth in vivo.
ST8SIA1 is also known as ganglioside GD3 synthase (GD3s) (26,27). It has been reported that ST8SIA1 is highly expressed in tumors. Yamashiro et al (28) examined the expression levels of ST8SIA1 in different tumor cell lines and found that it was highly expressed in melanoma, neuroblastoma and glioma cells. ST8SIA1 has also been shown to be highly expressed in triple-negative breast cancer (29). Previous studies have demonstrated that ST8SIA1 promotes the development of tumors by modulating GD3 and GD2 and by various other mechanisms of action. Cazet et al (30) demonstrated that ST8SIA1 overexpression induced the accumulation of GD2 and GD3 on the surface of MDA-MB-231 breast cancer cells, while it activated the downstream MEK/ERK and PI3K/Akt signaling pathways by activating $\mathrm{C}-\mathrm{MET}$, which in turn promoted the proliferation of tumor 


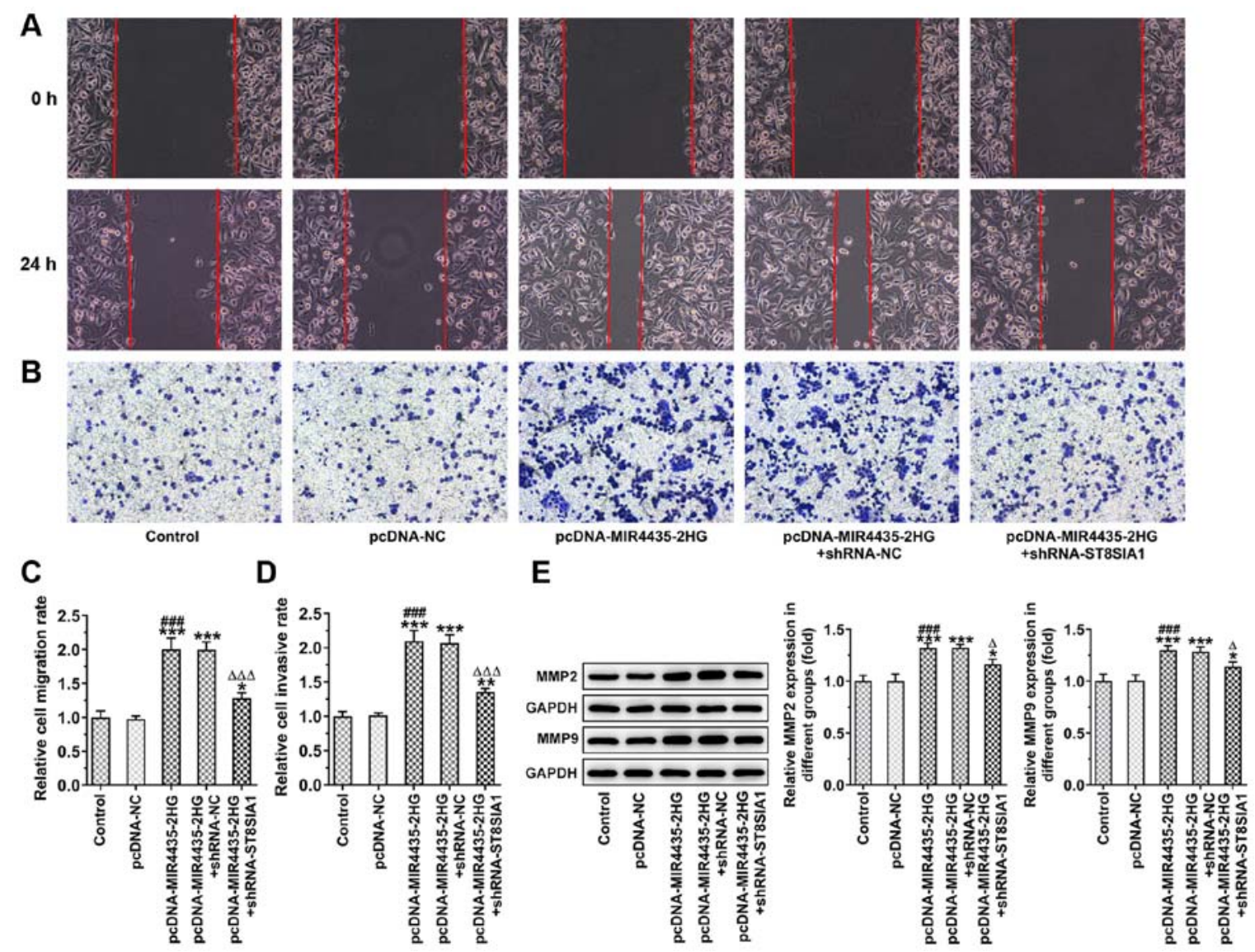

Figure 9. Interference with ST8SIA1 inhibits the promoting effects of MIR4435-2HG on the invasion and migration of prostate cancer cells. (A) Microscope images reflecting migration of PC-3 cells transfected with pcDNA-MIR4435-2HG and shRNA-ST8SIA1 (magnification, x100). (B) Microscope images reflecting the invasion of PC-3 cells transfected with pcDNA-MIR4435-2HG and shRNA-ST8SIA1 (magnification, x100). (C) The migration of PC-3 cells transfected with pcDNA-MIR4435-2HG and shRNA-ST8SIA1 was detected by wound healing assay. (D) The invasion of PC-3 cells transfected with pcDNA-MIR4435-2HG and shRNA-ST8SIA1 was detected by Transwell assay.(E) The MMP2 and MMP9 in PC-3 cells transfected with pcDNA-MIR4435-2HG and shRNA-ST8SIA1 was examined by western blot analysis. ${ }^{*} \mathrm{P}<0.05,{ }^{* *} \mathrm{P}<0.01$ and ${ }^{* * *} \mathrm{P}<0.001$ vs. control group; ${ }^{\# \# \#} \mathrm{P}<0.001$ vs. pcDNA-NC group. ${ }^{\Delta} \mathrm{P}<0.05$ and ${ }^{\Delta \Delta} \mathrm{P}<0.001$ vs. pcDNA-MIR4435-2HG + shRNA-NC group.

A

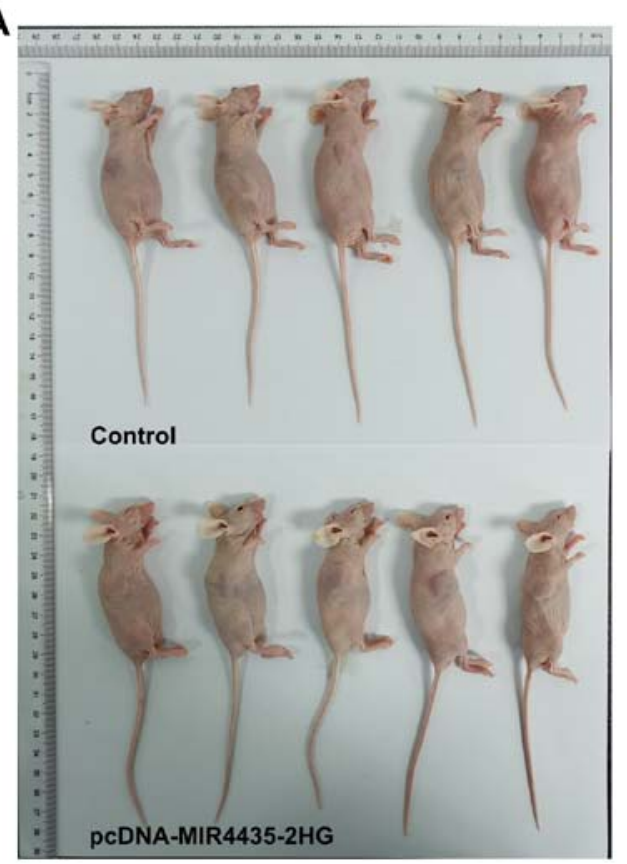

B
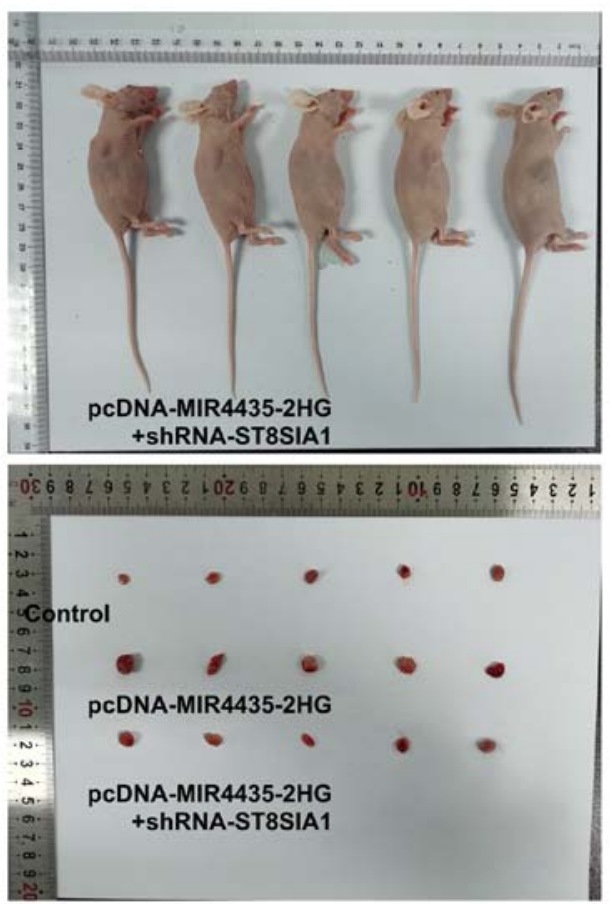

Figure 10. Interference with ST8SIA1 inhibits the promoting effects of MIR4435-2HG on the growth of prostate cancer cells in vivo. (A) The appearance of euthanized mice subcutaneously injected with PC-3 cells transfected with pcDNA-MIR4435-2HG and shRNA-ST8SIA1. (B) Tumor appearance. 
A

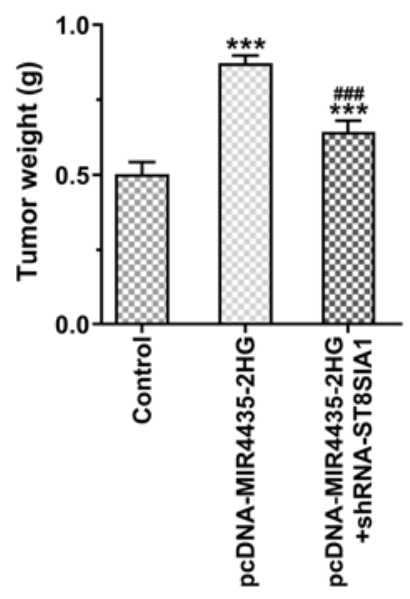

D

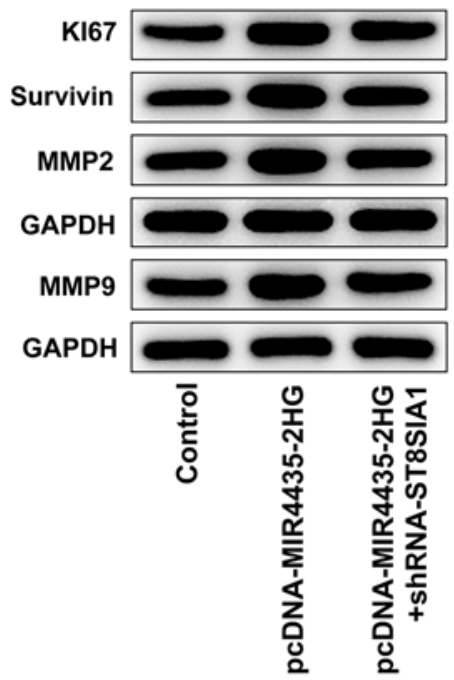

B $\rightarrow$ Control

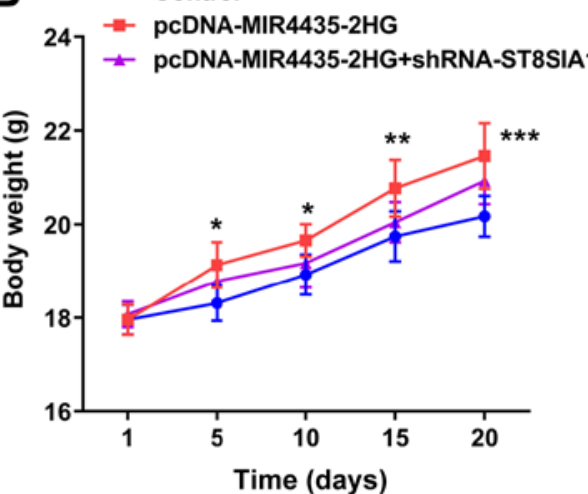

$\subseteq$
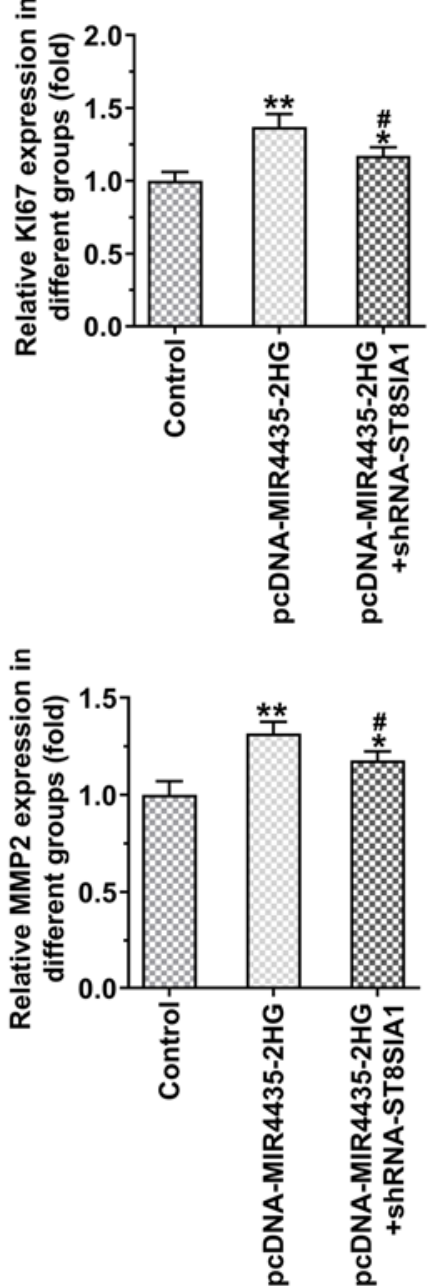
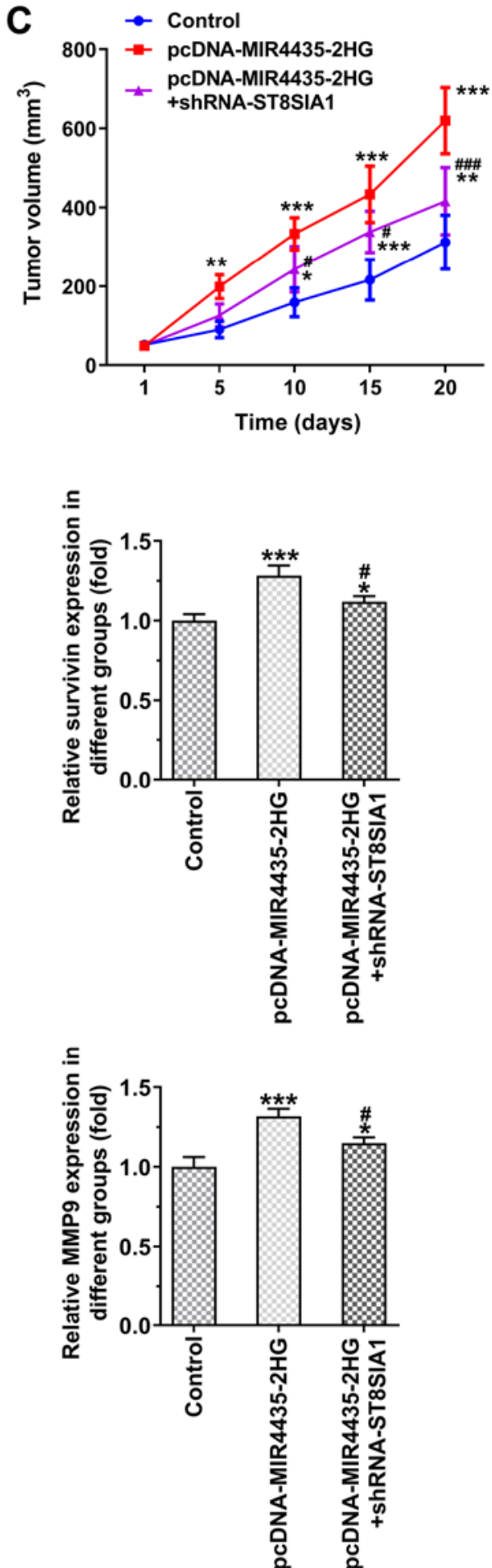

Figure 11. Interference with ST8SIA1 inhibits the promoting effects of MIR4435-2HG on the growth of prostate cancer cells in vivo. (A) Tumor weight. (B) Mouse body weight changes from the 1st to the 20th day. (C) Tumor volume changing from the 1st to the 20th day. (D) The expression of KI67, survivin, MMP2 and MMP9 in tumor tissues was detected by western blot analysis. ${ }^{*} \mathrm{P}<0.05,{ }^{* *} \mathrm{P}<0.01$ and ${ }^{* * *} \mathrm{P}<0.001$ vs. control group; ${ }^{\#} \mathrm{P}<0.05$ and ${ }^{\# \# \#} \mathrm{P}<0.001$ vs. pcDNA-MIR4435-2HG group.

cells. Moreover, ST8SIA1 stimulates the proliferation of melanoma cells (31). In SK-MEL-2 melanoma cells, NF- $\mathrm{BB}$ regulates the transcriptional activity of ST8SIA1 and affects the concentration of GD3 acting as a tumor suppressor (32). In the present study, ST8SIA1 expression was increased in prostate cancer cells and the knockdown of its expression impaired the role of MIR4435-2HG by suppressing the proliferation, invasion and migration of $\mathrm{PC}-3$ cells in vitro and their tumor growth in vivo.

FAK signaling plays a role in cell adhesion, migration and metastasis (33). FAK regulates various cellular activities including cell survival, adhesion, proliferation and migration by activating several signal transducers, such as PI3K, AKT and mTOR $(34,35)$. The knockdown of ST8SIA1 expression inhibits 


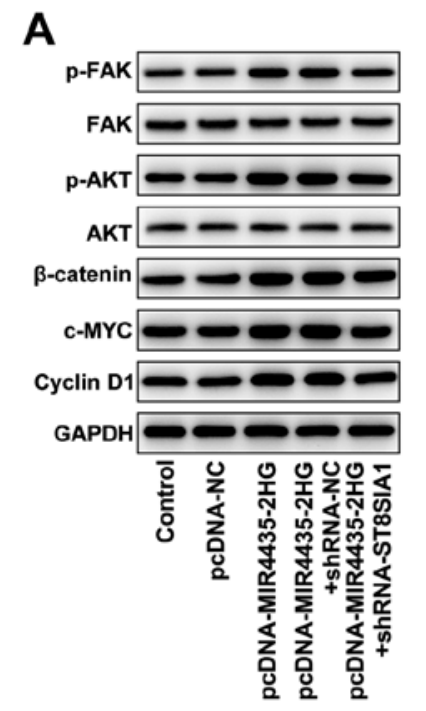

B

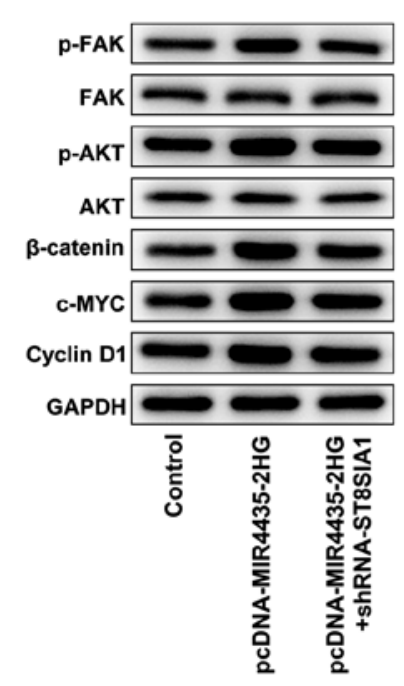

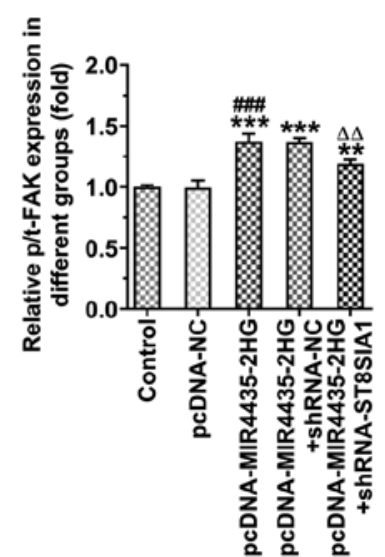
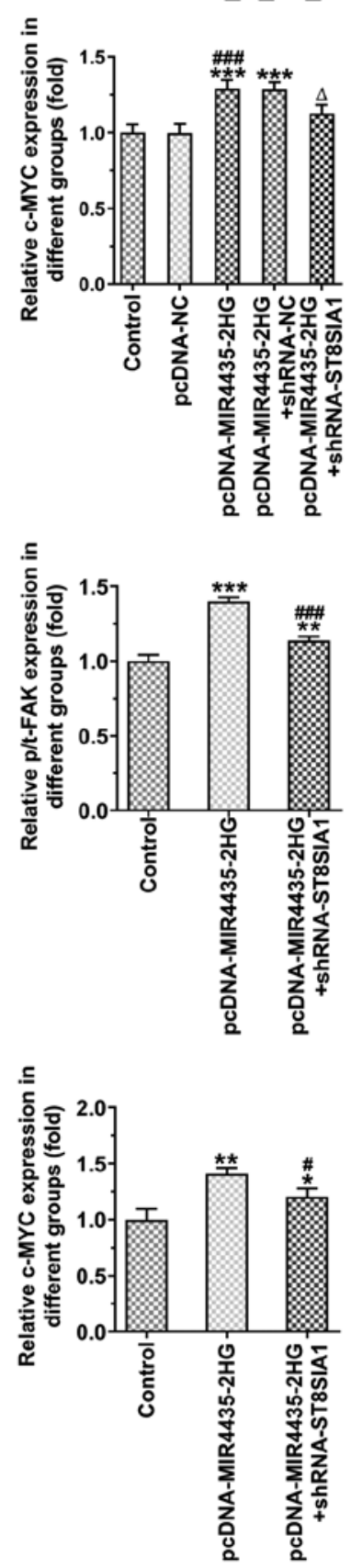
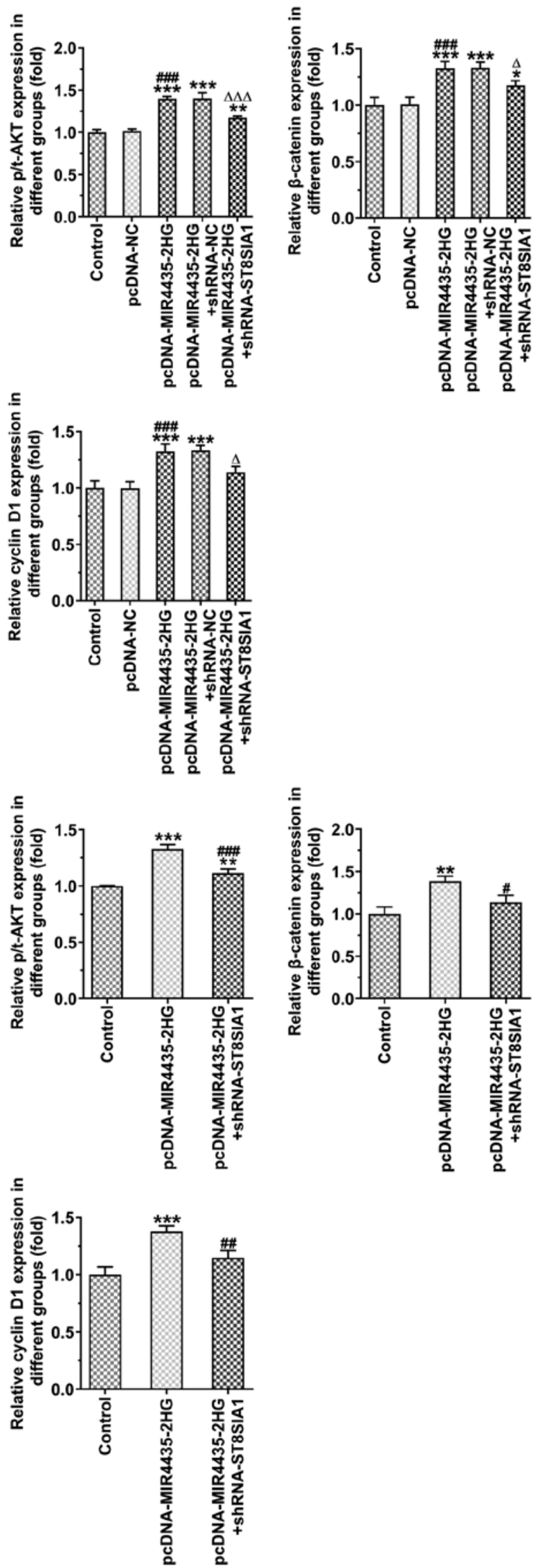

Figure 12. MIR4435-2HG overexpression activates the FAK/AKT/ $\beta$-catenin signaling pathway, which is inhibited by interference with ST8SIA1. (A) The expression of $\beta$-catenin, c-MYC and cyclin D1 in PC-3 cells transfected with pcDNA-MIR4435-2HG and shRNA-ST8SIA1 was detected by western blot analysis. ${ }^{*} \mathrm{P}<0.05,{ }^{* *} \mathrm{P}<0.01$ and ${ }^{* * *} \mathrm{P}<0.001$ vs. control group; ${ }^{\# \# "} \mathrm{P}<0.001$ vs. pcDNA-NC group. ${ }^{\Delta} \mathrm{P}<0.05,{ }^{\Delta \Delta} \mathrm{P}<0.01$ and ${ }^{\Delta \Delta \Delta} \mathrm{P}<0.001$ vs. pcDNA-MIR4435-2HG + shRNA-NC group. (B) The expression of $\beta$-catenin, c-MYC and cyclin D1 in tumor tissues of mice subcutaneously injected with PC-3 cells transfected with pcDNA-MIR4435-2HG and shRNA-ST8SIA1 was detected by western blot analysis. ${ }^{*} \mathrm{P}<0.05,{ }^{* * *} \mathrm{P}<0.01$ and ${ }^{* * * *} \mathrm{P}<0.001$ vs. control group; ${ }^{*} \mathrm{P}<0.05,{ }^{\# / t} \mathrm{P}<0.01$ and

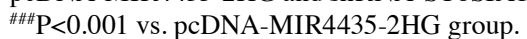


FAK/AKT/ERK/mTOR signaling in order to regulate the activity of breast cancer stem-like cells in triple-negative breast cancer (TNBC) (13). ST8SIA1 inhibition has been shown to suppress the FAK/Akt/mTOR pathway in chemoresistant TNBC cells and ST8SIA1 inhibition can cause the $\beta$-catenin degradation and subsequent reduction of Wnt/ $\beta$-catenin activity. In addition, a previous study reported the decreased phosphorylation of FAK at Y861, Akt at Ser473 and mTOR at Ser2448 in ST8SIA1-depleted MDA-MB-231-dox-r and BT 549-pac-r cells (36). In the present study, the knockdown of ST8SIA1 also suppressed the FAK/Akt/ $\beta$-catenin signaling pathway. p-AKT activates its downstream molecules. It can thus be hypothesized that the phosphorylation of FAK at Y861, Akt at Ser473 and mTOR at Ser2448 is also regulated by ST8SIA1; the authors aim to investigate this in future studies, as their functions are closely associated with tumor invasion and metastasis. The inhibition of AKT activation reduces the invasive and metastatic activities of multiple types of tumor cells (37). An increased AKT activity may increase the expression of the $\beta$-catenin protein in tumor cells and promote its nuclear entry and transcriptional activity, which accelerates the migration and invasion of tumor cells (38). The present study demonstrated that the in vitro proliferation, invasion and migration of PC-3 cells and tumor growth in vivo were suppressed by the inhibition of the FAK/AKT/ $\beta$-catenin signaling pathway. It was hypothesized that there may be other existing pathways through which MIR4435-2HG regulates FAK-AKT- $\beta$-catenin. MIR4435-2HG has been found to target miR-330; miR-330 has been demonstrated to regulate the PKC expression (39). miR-330 has been demonstrated to regulate the development of prostate cancer $(40,41)$. According to KEGG pathway analysis, the PKC gene is the upstream gene of FAK. MIR4435-2HG/miR-330/FAK upstream gene (PKC) may be the other pathway through which MIR4435-2HG regulates FAK/AKT/ $\beta$-catenin. In future studies, the authors aim to verify the combination of MIR4435-2HG and miR-330 and explore the mechanisms through which MIR4435-2HG regulates miR-330 expression. In the future, the authors also aim to investigate the effects of changes in miR-330 expression on the FAK/AKT/ $\beta$-catenin pathway.

In conclusion, the present study demonstrated that the knockdown of MIR4435-2HG expression inhibited the proliferation, invasion and migration of prostate cancer cells in vitro and in vivo, whereas the knockdown of ST8SIA1 expression inhibited the effects of miR4435-2HG on the in vitro proliferation, invasion and migration of PC-3 cells and on the in vivo tumor growth by suppressing the FAK/AKT/ $\beta$-catenin signaling pathway.

\section{Acknowledgements}

Not applicable.

\section{Funding}

The present study was funded by the National Key clinical specialist military construction project.

\section{Availability of data and materials}

The datasets used and/or analyzed during the current study are available from the corresponding author on reasonable request.

\section{Authors' contributions}

JL conceived and designed the experiments. PX and YW performed all the experiments with the assistance of LZ, and analyzed the experimental data with the assistance of CM. PX and YW confirm the authenticity of all the raw data. PX and YW wrote the manuscript which was revised by JL. All authors read and approved the final manuscript.

\section{Ethics approval and consent to participate}

All procedures involving animals were approved by the Animal Care and Use Committee of the First Affiliated Hospital of Naval Medical University.

\section{Patient consent for publication}

Not applicable.

\section{Competing interests}

The authors declare that they have no competing interests.

\section{References}

1. Bray F, Ferlay J, Soerjomataram I, Siegel RL, Torre LA and Jemal A: Global cancer statistics 2018: GLOBOCAN estimates of incidence and mortality worldwide for 36 cancers in 185 countries. CA Cancer J Clin 68: 394-424, 2018.

2. Zheng RS, Sun KX, Zhang SW, Zeng HM and He J: Report of cancer epidemiology in China, 2015. Zhonghua zhong liu za zhi (Article in Chinese) 41: 19-28, 2019.

3. Siegel RL, Miller KD and Jemal A: Cancer statistics, 2020. CA Cancer J Clin 70: 7-30, 2020.

4. Prensner JR, Iyer MK, Sahu A, Asangani IA, Cao Q, Patel L, Vergara IA, Davicioni E, Erho N, et al: The long noncoding RNA SChLAP1 promotes aggressive prostate cancer and antagonizes the SWI/SNF complex. Nat Genet 45: 1392-1398, 2013.

5. Yang J, Hao T, Sun J, Wei P and Zhang H: Long noncoding RNA GAS5 modulates $\alpha$-Solanine-induced radiosensitivity by negatively regulating miR-18a in human prostate cancer cells. Biomed Pharmacother 112: 108656, 2019.

6. Wu M, Huang Y, Chen T, Wang W, Yang S, Ye Z and Xi X: LncRNA MEG3 inhibits the progression of prostate cancer by modulating miR-9-5p/QKI-5 axis. J Cell Mol Med 23: 29-38, 2019.

7. Zhang Y, Zhang D, Lv J, Wang S and Zhang Q: LncRNA SNHG15 acts as an oncogene in prostate cancer by regulating miR-338-3p/FKBP1A axis. Gene 705: 44-50, 2019.

8. Yuan Q, Chu H, Ge Y, Ma G, Du M, Wang M, Zhang Z and Zhang W: LncRNA PCAT1 and its genetic variant rs1902432 are associated with prostate cancer risk. J Cancer 9: 1414-1420, 2018.

9. Li X, Ren Y and Zuo T: Long noncoding RNA LINC00978 promotes cell proliferation and invasion in non-small cell lung cancer by inhibiting miR-6754-5p. Mol Med Rep 18: 4725-4732, 2018.

10. Wang W, Xu Z, Wang J and Chen R: LINC00978 promotes bladder cancer cell proliferation, migration and invasion by sponging miR-4288. Mol Med Rep 20: 1866-1872, 2019.

11. Wang H,Wu M, Lu Y,He K, Cai X, Yu X, Lu J and Teng L: LncRNA MIR4435-2HG targets desmoplakin and promotes growth and metastasis of gastric cancer by activating Wnt/ $\beta$-catenin signaling. Aging (Albany NY) 11: 6657-6673, 2019.

12. Shen X, Ding Y, Lu F, Yuan H and Luan W: Long noncoding RNA MIR4435-2HG promotes hepatocellular carcinoma proliferation and metastasis through the miR-22-3p/YWHAZ axis. Am J Transl Res 12: 6381-6394, 2020.

13. Nguyen K, Yan Y, Yuan B, Dasgupta A, Sun V, Mu H, Do KA, Ueno NT, Andreeff $M$ and Battula VL: ST8SIA1 regulates tumor growth and metastasis in TNBC by activating the FAK-AKT-mTOR signaling pathway. Mol Cancer Ther 17: 2689-2701, 2018. 
14. Shan Y,Liu Y,Zhao L, Liu B, Li Y and Jia L: MicroRNA-33a and let-7e inhibit human colorectal cancer progression by targeting ST8SIA1. Int J Biochem Cell Biol 90: 48-58, 2017.

15. Chen Y, Deng X, Chen W, Shi P, Lian M, Wang H, Wang K, Qian D, Xiao D and Long H: Silencing of microRNA-708 promotes cell growth and epithelial-to-mesenchymal transition by activating the SPHK2/AKT/ $\beta$-catenin pathway in glioma. Cell Death Dis 10: 448, 2019.

16. Sun X, Xing G, Zhang C, Lu K, Wang Y and He X: Knockdown of Trop2 inhibits proliferation and migration and induces apoptosis of endometrial cancer cells via $\mathrm{AKT} / \beta$-catenin pathway. Cell Biochem Funct 38: 141-148, 2020.

17. Wei B, Wang Y, Wang JW, Cai X, Xu L, Wu J, Wang Y, Liu W, $\mathrm{Gu} \mathrm{Y,} \mathrm{Guo} \mathrm{W}$ and Xu Q: Apatinib suppresses tumor progression and enhances cisplatin sensitivity in esophageal cancer via the Akt/ $\beta$-catenin pathway. Cancer Cell Int 20: 198, 2020.

18. Livak KJ and Schmittgen TD: Analysis of relative gene expression data using real-time quantitative PCR and the 2(-Delta Delta C(T)) Method. Methods 25: 402-408, 2001

19. Tosoian JJ, Gorin MA, Ross AE, Pienta KJ, Tran PT and Schaeffer EM: Oligometastatic prostate cancer: Definitions, clinical outcomes, and treatment considerations. Nat Rev Urol 14: 15-25, 2017.

20. Pan B, Ye Y, Liu H, Zhen J, Zhou H, Li Y, Qu L, Wu Y, Zeng C and Zhong W: URG11 regulates prostate cancer cell proliferation, migration, and invasion. Biomed Res Int 2018: 4060728, 2018.

21. Bu JY, Lv WZ, Liao YF, Xiao XY and Lv BJ: Long non-coding RNA LINC00978 promotes cell proliferation and tumorigenesis via regulating microRNA-497/NTRK3 axis in gastric cancer. Int J Biol Macromol 123: 1106-1114, 2019.

22. Zhang Q, Cheng S, Cao L, Yang J, Wang Y and Chen Y: LINC00978 promotes hepatocellular carcinoma carcinogenesis partly via activating the MAPK/ERK pathway. Biosci Rep 40: BSR20192790, 2020.

23. Xu H, Zhang B, Yang Y, Yang Y, Li Z, Zhao P, Wu W, Zhang $\mathrm{H}$ and Mao J: LncRNA MIR4435-2HG potentiates the proliferation and invasion of glioblastoma cells via modulating miR-1224-5p/TGFBR2 axis. J Cell Mol Med 24: 6362-6372, 2020.

24. Dong X, Yang Z, Yang H, Li D and Qiu X: Long non-coding RNA MIR4435-2HG promotes colorectal cancer proliferation and metastasis through miR-206/YAP1 axis. Front Oncol 10: $160,2020$.

25. Shen H, Sun B, Yang Y, Cai X, Bi L, Deng L and Zhang L: MIR4435-2HG regulates cancer cell behaviors in oral squamous cell carcinoma cell growth by upregulating TGF- $\beta 1$. Odontology 108: 553-559, 2020.

26. Takashima S, Matsumoto T, Tsujimoto M and Tsuji S: Effects of amino acid substitutions in the sialylmotifs on molecular expression and enzymatic activities of $\alpha 2,8$-sialyltransferases ST8Sia-I and ST8Sia-VI. Glycobiology 23: 603-612, 2013

27. Rimoldi S, Papis E,Bernardini G,Prati M and Gornati R: Molecular cloning and expression of alpha2,8-sialyltransferase (ST8Sia I, GD3 Synthase) in xenopus. Mol Cell Biochem 301: 143-153, 2007.

28. Yamashiro S, Okada M, Haraguchi M, Furukawa K, Lloyd KO, Shiku $\mathrm{H}$ and Furukawa K: Expression of alpha 2,8-sialyltransferase (GD3 synthase) gene in human cancer cell lines: High level expression in melanomas and up-regulation in activated T lymphocytes. Glycoconjugate J 12: 894-900, 1995.

29. Sarkar TR, Battula VL, Werden SJ, Vijay GV, Ramirez-Peña EQ, Taube JH, Chang JT, Miura N, Porter W, Sphyris N, et al: GD3 synthase regulates epithelial-mesenchymal transition and metastasis in breast cancer. Oncogene 34: 2958-2967, 2015.
30. Cazet A, Lefebvre J, Adriaenssens E, Julien S, Bobowski M, Grigoriadis A, Tutt A, Tulasne D, Le Bourhis X and Delannoy P: $\mathrm{GD}_{3}$ synthase expression enhances proliferation and tumor growth of MDA-MB-231 breast cancer cells through c-Met activation. Mol Cancer Res 8: 1526-1535, 2010.

31. Birklé S, Gao L, Zeng G and Yu RK: Down-regulation of GD3 ganglioside and its $\mathrm{O}$-acetylated derivative by stable transfection with antisense vector against GD3-synthase gene expression in hamster melanoma cells: Effects on cellular growth, melanogenesis, and dendricity. J Neurochem 74: 547-554, 2000.

32. Kang NY, Kim CH, Kim KS, Ko JH, Lee JH, Jeong YK and Lee YC: Expression of the human CMP-NeuAc:GM3 alpha2,8-sialyltransferase (GD3 synthase) gene through the NF-kappaB activation in human melanoma SK-MEL-2 cells. Biochim Biophys Acta 1769: 622-630, 2007.

33. Luo M and Guan JL: Focal adhesion kinase: A prominent determinant in breast cancer initiation, progression and metastasis. Cancer Lett 289: 127-139, 2010.

34. Xia H, Nho RS, Kahm J, Kleidon J and Henke CA: Focal adhesion kinase is upstream of phosphatidylinositol 3-kinase/Akt in regulating fibroblast survival in response to contraction of type I collagen matrices via a beta 1 integrin viability signaling pathway. J Biol Chem 279: 33024-33034, 2004.

35. Jindra PT, Jin YP, Rozengurt E and Reed EF: HLA class I antibody-mediated endothelial cell proliferation via the mTOR pathway. J Immunol 180: 2357-2366, 2008.

36. Wan H, Li Z, Wang H, Cai F and Wang L: ST8SIA1 inhibition sensitizes triple negative breast cancer to chemotherapy via suppressing Wnt/ $\beta$-catenin and FAK/Akt/mTOR. Clin Transl Oncol 23: 902-910, 2020.

37. Qiao M, Iglehart JD and Pardee AB: Metastatic potential of $21 \mathrm{~T}$ human breast cancer cells depends on Akt/protein kinase B activation. Cancer Res 67: 5293-5299, 2007.

38. Zhang X, Chen T, Zhang J, Mao Q, Li S, Xiong W, Qiu Y, Xie Q and Ge J: Notch1 promotes glioma cell migration and invasion by stimulating $\beta$-catenin and NF- $\kappa \mathrm{B}$ signaling via AKT activation. Cancer Sci 103: 181-190, 2012.

39. Liu J, Liu L, Chao S, Liu Y, Liu X, Zheng J, Chen J, Gong W, Teng H, Li Z, et al: The role of miR-330-3p/PKC- $\alpha$ signaling pathway in low-dose endothelial-monocyte activating polypeptide-II increasing the permeability of blood-tumor barrier. Front Cell Neurosci 11: 358, 2017.

40. Liu DC, Song LL, Liang Q, Hao L, Zhang ZG and Han CH: Long noncoding RNA LEF1-AS1 silencing suppresses the initiation and development of prostate cancer by acting as a molecular sponge of miR-330-5p via LEF1 repression. J Cell Physiol 234: $12727-12744,2019$

41. Li Q, Wang W, Zhang M, Sun W, Shi W and Li F: Circular RNA circ-0016068 promotes the growth, migration, and invasion of prostate cancer cells by regulating the miR-330-3p/BMI-1 axis as a competing endogenous RNA. Front Cell Dev Biol 8: 827, 2020.

This work is licensed under a Creative Commons Attribution-NonCommercial-NoDerivatives 4.0 International (CC BY-NC-ND 4.0) License. 